\title{
Thermally Stable Multilamellar Structure of DNA/Cationic Lipid Complex in the Bulk State
}

\author{
Ching-Mao $\mathrm{Wu}^{*}$ and Szu-Yin Lin
}

\begin{abstract}
Material and Chemical Research Laboratories, Industrial Technology Research Institute, Chutung, Hsin-Chu, 310, Taiwan
\end{abstract}

\begin{abstract}
The effect of temperature on the two types of multilamellar structures, $L_{1}$ and $L_{11}$, formed by the complexes of DNA with a cationic lipid, cholesteryl $3 \beta-\mathrm{N}$-(dimethylamionethyl) carbamate (DC-Chol), in the bulk state has been investigated by small angle X-ray scattering (SAXS). $L_{1}$ phase composing of A-DNA intercalated between the lipid bilayers with tilted tails was formed at lower lipid-to-base pair molar ratio $(x<2)$, while $L_{\|}$phase consisting of $B-D N A$ bound to untilted lipid was formed at $x>2$. In addition to the differences in lipid packing state and DNA conformation, these two lamellar phases also displayed different thermal stability. $L_{1}$ phase was highly thermally stable as its interlamellar distance remained essentially unperturbed even after the denaturation of A-DNA in the complex at elevated temperature. By contrast, the interlamellar distance of $L_{\|}$phase decreased with increasing temperature due to the release of bound water and B-DNA denaturation.
\end{abstract}

Keywords: DNA-lipid complex, Lipid, DNA condensation, DC-Chol, SAXS.

\section{INTRODUCTION}

Self-assembly of DNA/cationic lipid (CL) complexes in aqueous media has drawn significant attention largely because of their applications as nonviral vectors in gene therapy [1-6]. Recently, interests have also been directed toward the understandings of this type of complexes in the bulk state due to their potential applications as self-assembled functional materials [712]. For instance, an water-insoluble and aligned DNA/CL film has been prepared as a molecular material which may exhibit one-dimensional electron transfer and conduction along the DNA strands $[7,8]$. Unlike the extensively studied bulk complexes of synthetic polyelectrolytes with oppositely charged surfactants, understanding on the structures and physicochemical properties of DNA/CL complexes in the bulk state is still limited, especially on how the structure evolves from the aqueous media to the bulk state and the stability of the structure with respect to the perturbations such as heat and external fields.

Typically, the addition of DNA into the $\mathrm{CL}$ aqueous dispersion induces the aggregation of the vesicles or micelles of the $C L$ to form compact particles with ordered internal structure [3-6,13-15]. The ordered structures observed thus far include a multilamellar phase $\left(\mathrm{L}_{\alpha}{ }^{\mathrm{C}}\right)$ consisting of alternating lipid bilayer and DNA monolayer [3,4] and an inverted hexagonal phase $\left(\mathrm{H}_{\|}{ }^{\mathrm{C}}\right)$ in which the DNA chains contained within lipid tubes arrange in a hexagonal lattice [5]. Since these

*Address correspondence to this author at the Material and Chemical Research Laboratories, Industrial Technology Research Institute, Chutung, Hsin-Chu, 310, Taiwan; Tel: +886-3-5918245; Fax: +886-3-5820215;

E-mail: ChingMaoWu@itri.org.tw structures were formed in the presence of excess water, the DNA phosphate groups were sufficiently hydrated such that the DNA chains in the complex adopted the common B conformation (i.e., B-DNA) $[4 a, b]$. In the bulk state where most water has been removed and only some water molecules are bound to phosphate groups of DNA and head groups of lipid due to ionic characteristics of DNA and CL, the secondary structure of DNA in the complex may deviate from the B conformation. Okahata et al. [7] used circular dichroism (CD) to examine the DNA conformation in the complexes with $\mathrm{N}, \mathrm{N}, \mathrm{N}$-trimethyl-N-(3,6,9,12tetraoxadocosyl) ammonium bromide in the dry film and aqueous media. Their results revealed a B-A conformational transition from wet to dry state [7]. Recently we have studied the structure of the complexes of DNA with a CL, cholesteryl $3 \beta-N-$ (dimethylamionethyl) carbamate (DC-Chol), in the hydrate and bulk state using small angle $\mathrm{X}$-ray scattering (SAXS) $[15,16]$. The complexes in the hydrate state were found to exhibit a multilamellar structure in which the DNA confined in the hydrophilic layers adopted B conformation. Both the interlamellar distance $(\approx 6.28 \mathrm{~nm})$ and the in-plane interhelical distance of DNA ( $d_{D N A} \approx 2.5 \mathrm{~nm}$ ) were independent of the lipid-to-base pair molar ratio $(x)$ [15]. When most water was removed, the complexes with $x$ lying above the isoelectric composition $(x>2)$ displayed a multilamellar structure (denoted by $L_{\|}$phase) identical to that formed in the hydrate state in terms of the interlamellar distance and DNA conformation. By contrast, the complex with $\mathrm{x}<2$ showed another multilamellar structure (denoted by $L_{1}$ phase) consisting of A-form DNA intercalated between the lipid bilayers with tilted tails $[4 c, 16]$. 
In the present study, we proceed further to reveal the effect of temperature on the multilamellar structures of DNA/DC-Chol complexes in the bulk state. It will be shown that in addition to the differences in lipid packing state (tilted vs. untilted tails) and DNA conformation (A vs. $B$ form), $L_{l}$ and $L_{\|}$phase also exhibit different thermal stability as the interlamellar distance of $L_{\|}$ phase decreases with increasing temperature due to the release of bound water and DNA denaturation, whereas $L_{l}$ phase remains essentially unperturbed upon heating despite of DNA denaturation.

\section{EXPERIMENTAL SECTION}

\section{Materials and Sample Preparation}

DNA type XIV from herring testes with the average molecular weight of ca. 700 base pairs (bp) and the CL, DC-Chol, were acquired from Sigma. DNA/DC-Chol complexes in the bulk state were prepared by mixing prescribed amounts of DNA aqueous solution (10 $\mathrm{mg} / \mathrm{mL}$ ) with the DC-Chol aqueous suspension. The complexes formed spontaneously as manifested by precipitation. The solution containing the precipitate was then allowed to dry slowly at room temperature under ambient atmosphere. The overall complex composition is denoted by $\mathrm{x}$, which expresses the lipidto-bp molar ratio; $\mathrm{x}=2.0$ corresponds to the stoichiometric (or isoelectric) composition for charge neutralization. Here we center on the complexes with $x$ $=0.75$ and 3.0 displaying $L_{\mid}$and $L_{\| 1}$ phase, respectively.

\section{SAXS Measurements}

The structures of DNA/DC-Chol complexes were probed with a Bruker NanoSTAR SAXS instrument, which consisted of a Kristalloflex K760 $1.5 \mathrm{~kW}$ X-ray generator (operated at $40 \mathrm{kV}$ and $35 \mathrm{~mA}$ ) and crosscoupled Göbel mirrors for $\mathrm{Cu}$ Ka radiation $(\lambda=1.54 \AA)$ resulting in a beam of about $0.05 \mathrm{~mm}^{2}$ in cross section at the sample position. The scattering intensity was detected by a Siemens multiwire type area detector with $1024 \times 1024$ resolution mode. All the SAXS data had been corrected for empty beam scattering background and the sensitivity of each pixel of the area detector. The area scattering pattern was circularly averaged to increase the photon counting efficiency compared with the one-dimensional linear detector. The resulting intensity profile was output as a plot of the scattering intensity $(\mathrm{I})$ versus the scattering vector, $q=(4 \pi / \lambda) \sin (\theta / 2) \quad(\theta=$ scattering angle $)$. For the temperature-dependent measurements, the sample was first thermally equilibrated at the desired temperature for 10 minutes followed by data acquisition for 60 minutes. All the intensity profiles reported here had also been corrected for the thermal diffuse scattering (TDS). TDS was considered as a positive deviation from Porod's law and might be associated with thermal motion, local disorder, or onset of wideangle scattering region. The intensity level of TDS was assumed to be a constant, and its magnitude was determined from the slope of $\mathrm{Iq}^{4}$ versus $\mathrm{q}^{4}$ plot in the high-q region.

\section{RESULTS AND DISCUSSION}

Figure 1 displays the temperature-dependent SAXS profiles collected in a heating cycle from 30 to $190{ }^{\circ} \mathrm{C}$ for DNA/DC-Chol complexes with $x=0.75$ (Panel a) and $x=3.0$ (Panel $b$ ), which exhibit $L_{1}$ and $L_{\| 1}$ phase, respectively. The interlamellar distance (d) of $L_{1}$ phase is about $1.2 \mathrm{~nm}$ smaller than that of $L_{\|}$phase due to the tilting of the lipid tails for more economical electrostatic binding with DNA [16]. It is noted that the denaturation of DNA in the complexes is found to occur near $80 \sim 90$ ${ }^{\circ} \mathrm{C}$ from the differential scanning calorimetry (DSC) heating scan [17-19]. Therefore, the temperature range adopted for the SAXS experiment has covered the denaturation region of DNA. It can be seen from Figure 1a that the SAXS pattern of the complex $(x=0.75)$ exhibiting $L_{1}$ phase is virtually unperturbed by the heating, signaling that the multilamellar structure with $d$ $=4.4 \mathrm{~nm}$ remains stable throughout the heating even after the DNA chains in the complex has denatured. By contrast, although the complex $(x=3.0)$ showing $L_{\|}$ phase displays multilamellar structure over the entire temperature window, the corresponding interlamellar distance decreases from 5.6 to $4.76 \mathrm{~nm}$ on heating from 30 to $190{ }^{\circ} \mathrm{C}$. It is noted that a small broad peak marked by $\mathrm{q}_{\mathrm{DNA}}$ is observed at $30{ }^{\circ} \mathrm{C}$ for this composition (as shown more clearly in the inset of Figure 1b). This peak is attributed to the in-plane correlation of the DNA chains arranged in a smectic order in the hydrophilic layers $[4,16]$. The corresponding interhelical distance $d_{D N A}$ calculated by $\mathrm{d}_{D N A}=2 \pi / q_{D N A}$ is ca. $2.55 \mathrm{~nm}$. When the temperature is raised to $50{ }^{\circ} \mathrm{C}$, the qDNA peak vanishes due to the loss of bound water that regulates the ordered arrangement of the DNA chains.

Figure 2 displays the SAXS profiles of pure DCChol in the bulk for examining the thermal stability of the membrane without the presence of DNA. Similar to the complex with $x=0.75$, the multilamellar structure with $\mathrm{d}=4.3 \mathrm{~nm}$ remains intact upon heating to $190{ }^{\circ} \mathrm{C}$. The good thermal stability of the membrane is 
(a)

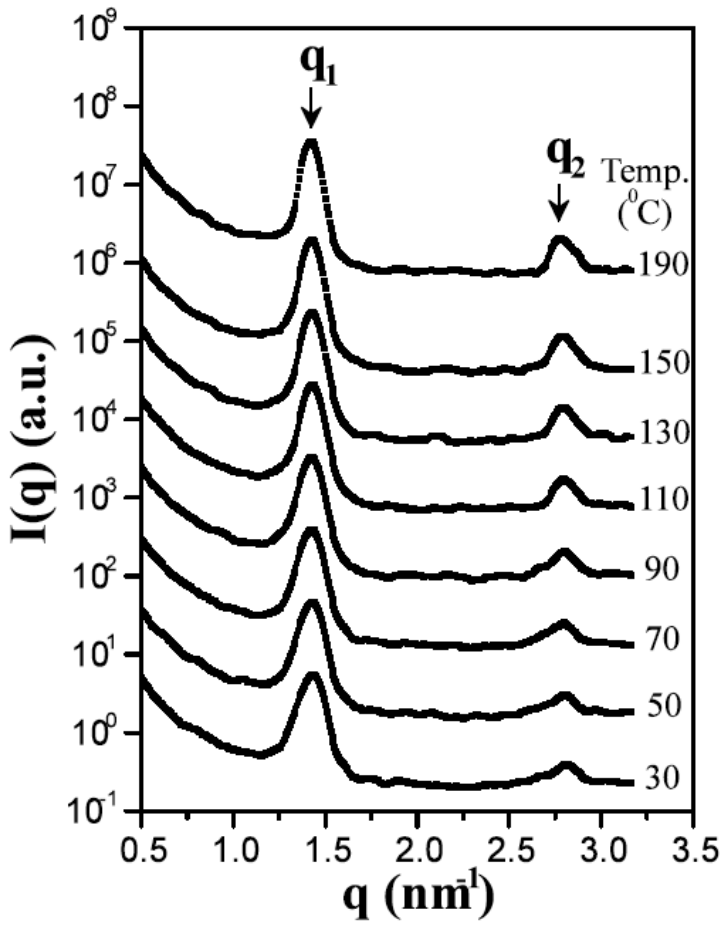

(b)

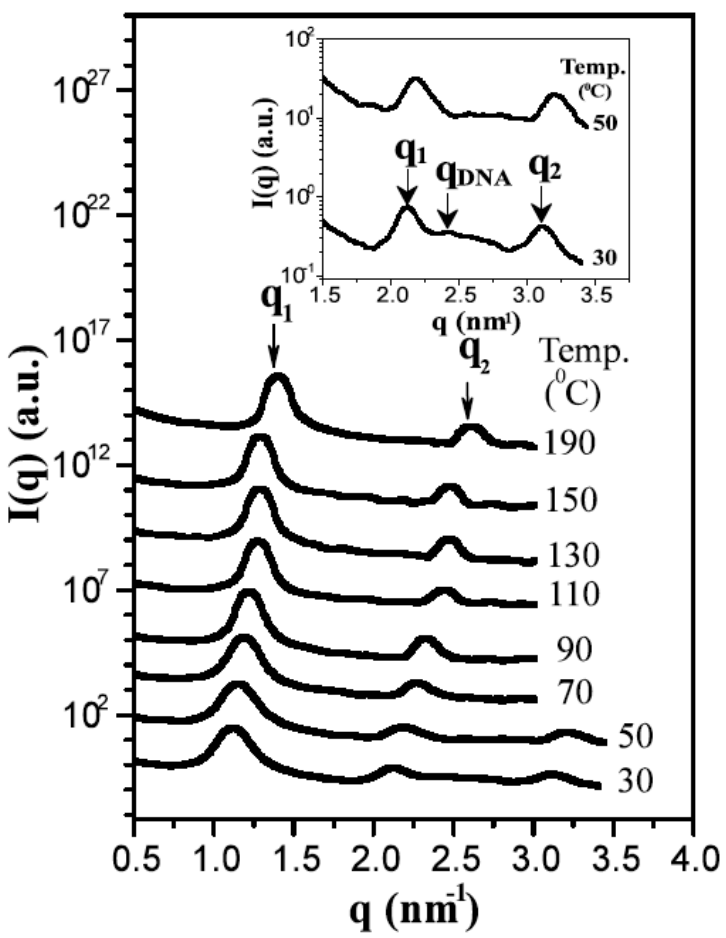

Figure 1: Temperature-dependent SAXS profiles of DNA/DC-Chol complexes with (a) $x=0.75$ and (b) $x=3.0$ in the bulk state. The inset in (b) is the enlarged plot of the intensity profile between 1.5 and $3.5 \mathrm{~nm}^{-1}$ to show the presence of a broad qDNA peak at $30{ }^{\circ} \mathrm{C}$.

prescribed by the rigid cholesteryl tail of the DC-Chol molecule. We expect the hydrophobic layers in the complex to retain such a good thermal stability. Consequently, it is reasonable to consider the reduction of the interlamellar distance of $L_{\| 1}$-forming complex to stem from the thinning of the hydrophilic layers due to the loss of bound water coupled with DNA denaturation upon heating.

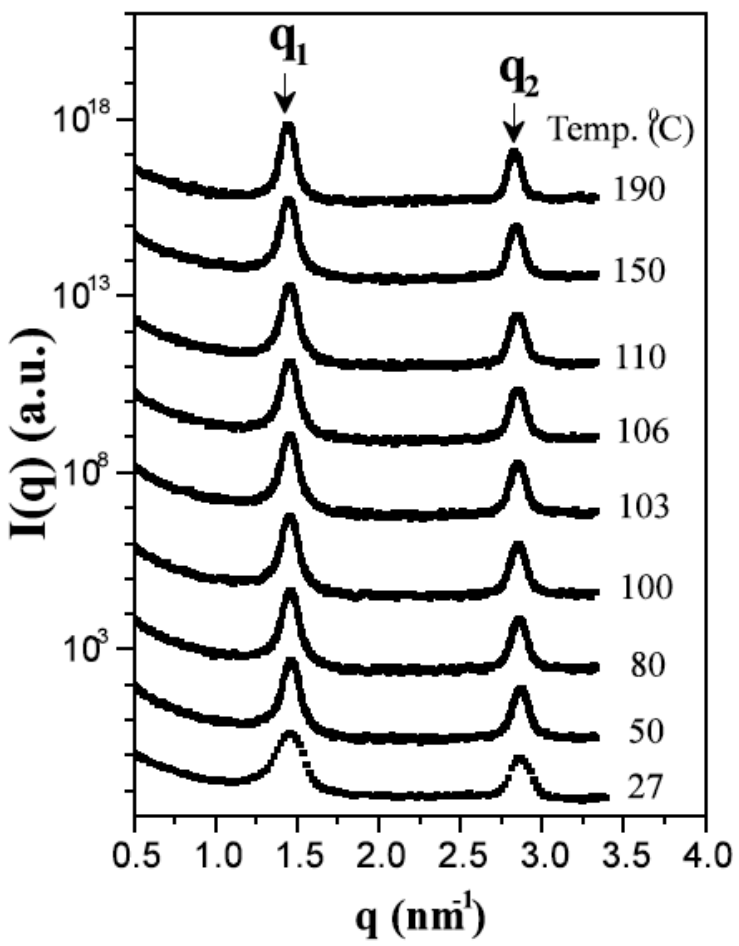

Figure 2: Temperature-dependent SAXS profiles of pure DCChol in the bulk state.

From the previous analyses of the electron density profiles, the average thickness of the hydrophobic layer $\left(d_{m}\right)$ in the $L_{\| 1}$ and $L_{1}$ phase was found to be ca. $1.92 \mathrm{~nm}$ and $1.5 \mathrm{~nm}$, respectively [16]. Assuming that $\mathrm{d}_{\mathrm{m}}$ is unperturbed by the heating, the hydrophilic layers thickness $\left(d_{w}\right)$ at various temperatures can then be obtained easily from $d_{w}=d-d_{m}$. Figure 3 plots $d_{w}$ thus deduced as a function of temperature for the $L_{11}$-forming complex $(x=3.0)$. It can be seen that $d_{w}$ decreases progressively with increasing temperature from 30 to $110{ }^{\circ} \mathrm{C}$. The drop of $\mathrm{d}_{\mathrm{w}}$ with increasing temperature is ascribed to the gradual loss of bound water accompanied with the denaturation of B-DNA in the complex. Both $d$ and $d_{w}$ become independent of temperature above $110{ }^{\circ} \mathrm{C}$ as the system exhibits another thermally stable multilamellar structure consisting of denatured DNA. This lamellar phase is denoted by $L_{\|}{ }^{d}$.

In contrast to $L_{\|}$phase, $L_{1}$ phase exhibits a high thermal stability even under the mediation of the denaturation of A-DNA intercalated between the bilayers. Figure 4 schematically presents our explanation for the observed difference in thermal stability. As shown in Figure $\mathbf{4 a}, L_{\|}$phase at lower 




Figure 3: Variations of hydrophilic layer thickness $\left(d_{w}\right)$ and interlamellar distance (d) with temperature for DNA/DC-Chol complex with $x=3.0$ in the bulk state.

temperature ( $T<$ DNA denaturation temperature) composes of B-DNA bound with untilted DC-Chol lipid. The corresponding $d_{D N A}$ is ca. $2.5 \mathrm{~nm}$. Subtracting the diameter of B-DNA $(=2.0 \mathrm{~nm})$ from $\mathrm{d}_{\mathrm{DNA}}$, then we can identify an extra gap of ca. $0.5 \mathrm{~nm}$ situating between DNA chains and these spaces should be filled with water molecules. When the system is heated, these water molecules gradually escape from the complex to gain entropy and above a certain temperature this process is accompanied with DNA denaturation. To maintain a uniform mass density in the hydrophilic layers, the voids originally occupied by the water will have to be re-filled by the denatured DNA chains and this causes the reduction of $d_{w}$. Conversely, for the $L_{1}$ phase containing A-DNA bound with tilted DC-Chol lipids, the A-DNA chains form closest packing in the hydrophilic layers because the $d_{D N A}$ of $2.5 \mathrm{~nm}$ is close to the diameter of A-DNA $(2.3 \sim 2.55 \mathrm{~nm})$. In this case, there is almost no water gap between the DNA chains (Figure 4b). Thus, even though the DNA chains denature upon heating, the denatured DNA chains are still pinned to their original positions. As a result, a single multilamellar structure with a fixed $d$ is observed throughout the heating process.

\section{CONCLUSIONS}

In conclusion, we have revealed the temperature effect on the multilamellar structures formed by

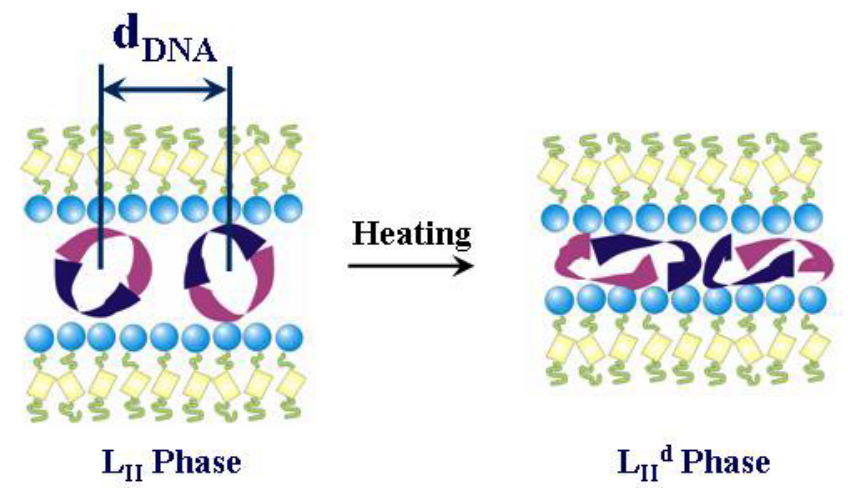

(a)


(b)

Figure 4: Schematic illustrations of the structural changes of DNA/DC-Chol complexes upon heating: (a) transformation of $L_{\|}$ phase to another multilamellar phase with denatured B-DNA chains; (b) transformation of $L_{\text {। }}$ phase to another lamellar phase with denatured A-DNA chains. The interlamellar distance decreases due to the thinning of the hydrophilic layers in (a), whereas $\mathrm{d}$ is essentially unperturbed in (b). The two complementarily strands forming one duplex are marked by two colors in the scheme. 
DNA/DC-Chol complexes in the bulk. The $\mathrm{L}_{1}$-forming complex exhibits a highly thermally stable multilamellar structure in the sense that the interlamellar distance remains unperturbed even after the denaturation of $A$ DNA in the complex. By contrast, the interlamellar distance of $L_{\|}$phase decreases with increasing temperature due to the release of bound water and DNA denaturation. Our results disclose a bioassembly with highly thermally stable structure even after the disruption of the secondary structure of the constituting DNA molecules.

\section{ACKNOWLEDGEMENT}

We gratefully acknowledge financial support from Industrial Technology Research Institute, Taiwan.

\section{REFERENCES}

[1] Felgner PL, Gadek TR, Holm M, Roman R, Chan HW, Wenz $\mathrm{M}$, et al. Lipofection: A highly efficient, lipid-mediated DNA transfection procedure. Proc Natl Acad Sci USA 1987; 84: 7413-7.

http://dx.doi.org/10.1073/pnas.84.21.7413

[2] Miller AD. Cationic liposomes for gene therapy. Angew Chem Int Ed 1998; 37: 1768-85.

http://dx.doi.org/10.1002/(SICI)15213773(19980803)37:13/14<1768::AID-ANIE1768>3.0.CO;2-4

[3] Lasic DD, Strey H, Stuart MCA, Podgornik R, Frederik PM. The structure of DNA-liposome complexes. J Am Chem Soc 1997; 119: 832-3.

http://dx.doi.org/10.1021/ja962713g

(a) Rädler JO, Koltover I, Salditt T, Safinya CR. Structure of DNA-cationic liposome complexes: DNA intercalation in multilamellar membranes in distinct interhelical packing regimes. Science 1997; 275: 810-4 http://dx.doi.org/10.1126/science.275.5301.810

(b) B-DNA consists of an alpha helix (right-handed) with approximately 10 base pairs per turn (360-degree rotation of the helix). Its helix pitch is $\sim 3.4 \mathrm{~nm}$ and diameter of ca. 2.0 $\mathrm{nm}$. Because the hydrophilic phosphate groups lie in the outer of the helix, this structure exists when plenty of water surrounds the molecules.

(c) A-DNA is another secondary structure, which is also an alpha helix and exists when less water is present. A-DNA with diameter of $\sim 2.55 \mathrm{~nm}$ and pitch of $2.8 \mathrm{~nm}$ is shorter and wider than B-DNA.

[5] Koltover I, Salditt T, Rädler JO, Safinya CR. An inverted hexagonal phase of cationic liposome-DNA complexes related to DNA release and delivery. Science 1998; 281: 7881.

http://dx.doi.org/10.1126/science.281.5373.78

[6] Koltover I, Salditt T, Safinya CR. Phase Diagram, Stability, and Overcharging of Lamellar Cationic Lipid-DNA SelfAssembled Complexes. Biophys J 1999; 77: 915-24. http://dx.doi.org/10.1016/S0006-3495(99)76942-0
[7] Tanaka K, Okahata Y. A DNA-lipid complex in organic media and formation of an aligned cast film. J Am Chem Soc 1996; 118: 10679-3.

http://dx.doi.org/10.1021/ja9617855

[8] Okahata $\mathrm{Y}$, Kobayashi T, Tanaka K, Shimomura M Anisotropic electric conductivity in an aligned DNA cast film. J Am Chem Soc 1998; 120: 6165-6. http://dx.doi.org/10.1021/ja980165w

[9] Ikkala O, ten Brinke G. Functional materials based on self assembly of polymeric supramolecules. Science 2002; 295: 2407-9.

http://dx.doi.org/10.1126/science.1067794

[10] Fukushima T, Hayakawa T, Inoue Y, Miyazaki K, Okahata $Y$. Intercalation behavior and tensile strength of DNA-lipid films for the dental application. Biomaterials 2004; 25: 5491-7. http://dx.doi.org/10.1016/j.biomaterials.2004.01.006

[11] Cui L, Miao J, Zhu L. Spacer length controlled obliquecolumnar to lamello-columnar mesophase transition in liquid crystalline DNA-discotic cationic lipid complexes. Macromolecules 2006; 39: 2536-45. http://dx.doi.org/10.1021/ma060001x

[12] Wu CM, Lin SY. Nanostructures and Thermal Properties of the Binary Mixture of DNA and a Zwitterionic Phospholipid in the Bulk. J. Appl. Sol. Chem. Model. 2012:1: 79-88. http://dx.doi.org/10.6000/1929-5030.2012.01.02.1

[13] Zhou S, Liang D, Burger C, Yeh F, Chu B. Nanostructures of Complexes Formed by Calf Thymus DNA Interacting with Cationic Surfactants. Biomacromolecules 2004; 5: 1256-61. http://dx.doi.org/10.1021/bm034524d

[14] Wu CM, Chen CY, Lin SY, Chen HL. Effect of divalent cations on DNA condensed on the surface of rigid cationic membrane. React Funct Polym 2011; 71: 266-71. http://dx.doi.org/10.1016/j.reactfunctpolym.2010.09.009

[15] Wu CM, Liou W, Chen HL, Lin TL, Jeng US. Self-assembled structure of the binary complex of DNA with cationic lipid. Macromolecules 2004; 37: 4974-80. http://dx.doi.org/10.1021/ma049541p

[16] Wu CM, Chen HL, Lin TL, Liou W, Lin JS. A two-state model for the multilamellar structure of a DNA/cationic lipid complex in the bulk. Langmuir 2004; 20: 9432-6. http://dx.doi.org/10.1021/la0488856

[17] The denaturation temperature of DNA in the complexes was measured by using a TA Instrument 2000 differential scanning calorimeter (DSC) equipped with the RCS cooling system. The samples were heated from -10 to $200{ }^{\circ} \mathrm{C}$ at a rate of $5{ }^{\circ} \mathrm{C} / \mathrm{min}$. The denaturation was found to give rise to an endothermic peak. The peak temperature was taken as the denaturation temperature $\left(T_{d}\right)$ of DNA. The $T_{d}$ thus measured was $84{ }^{\circ} \mathrm{C}$ and $89{ }^{\circ} \mathrm{C}$ for the $\mathrm{L}_{1}$ - and $\mathrm{L}_{\| 1}$-forming complex, respectively.

[18] Tarahovsky YS, Rakhmanova VA, Epand RM, MacDonald RC. High temperature stabilization of DNA in complexes with cationic lipids.High temperature stabilization of DNA in complexes with cationic lipids. Biophys J 2002; 82: 264-73. http://dx.doi.org/10.1016/S0006-3495(02)75392-7

[19] Lee SL, Debenedetti PG, Errington JR, Pethica BA, Moore DJ. A Calorimetric and Spectroscopic Study of DNA at Low Hydration. J Phys Chem B 2004; 108: 3098-106. http://dx.doi.org/10.1021/jp0311409 